\title{
Leishmanicidal activity of carvacrol-rich essential oil from Lippia sidoides Cham
}

\author{
Paulo A Farias-Junior ${ }^{1}$, Marcos C Rios ${ }^{1}$, Tauanny A Moura ${ }^{2}$, Roque P Almeida², Pericles B Alves ${ }^{3}$, Arie F Blank ${ }^{4}$, \\ Roberta P M Fernandes ${ }^{1}$, Ricardo Scher ${ }^{5 *}$
}

${ }^{1}$ Departamento de Fisiologia, Universidade Federal de Sergipe, Av. Marechal Rondon, São Cristóvão, Sergipe, Brasil
${ }^{2}$ Departamento de Medicina, Universidade Federal de Sergipe, Rua Claudio Batista, Aracaju, Sergipe, Brasil
${ }^{3}$ Departamento de Química, Universidade Federal de Sergipe, Av. Marechal Rondon, São Cristóvão, Sergipe, Brasil
${ }^{4}$ Departamento de Agronomia, Universidade Federal de Sergipe, Av. Marechal Rondon, São Cristóvão, Sergipe, Brasil
${ }^{5}$ Departamento de Morfologia, Universidade Federal de Sergipe, Av. Marechal Rondon, São Cristóvão, Sergipe, Brasil

\section{ABSTRACT}

Leishamaniasis is a disease that affects more than 2 million people worldwide, whose causative agent is Leishmania spp. The current therapy for leishmaniasis is far from satisfactory. All available drugs, including pentavalent antimony, require parenteral administration and are potentially toxic. Moreover, an increase in clinical resistance to these drugs has been reported. In this scenario, plant essential oils used traditionally in folk medicine are emerging as alternative sources for chemotherapeutic compounds. In this study, in vitro leishmanicidal effects of a thymol- and a carvacrol-rich essential oil from leaves of Lippia sidoides Cham. were investigated. The essential oils were extracted and their constituents were characterized by gas chromatography coupled to mass spectrometry (GC/MS). Both essential oils showed significant activity against promastigote forms of Leishmania chagasi. However, we found that carvacrol-rich essential oil was more effective, with $\mathrm{IC}_{50} / 72 \mathrm{~h}$ of $54.8 \mu \mathrm{g} / \mathrm{mL}$ compared to $74.1 \mu \mathrm{g} / \mathrm{mL}$ for thymol-rich oil. Carvacrol also showed lower $\mathrm{IC}_{50}$ than thymol. Our data suggest that $L$. sidoides essential oils are indeed promising sources of leishmanicidal compounds.

Key words: carvacrol, p-cymene, essential oil composition, Leishmania chagasi, Lippia ssp., thymol, Verbenaceae.

\section{INTRODUCTION}

Natural products obtained from a wide range of plant species, such as essential oils, have been traditionally used to treat a number of diseases, including leishmaniasis (Hammer and Johns, 1993; Franca et al., 1996; Bezerra et al., 2006).

The causative agent of leishamaniasis is a parasitic protozoan of the genus Leishmania (Trypanosomatidae) which is transmitted to humans by sand flies, either of the genus Phlebotomus (Old World) or Lutzomyia (New World). According to the World Health Organization, leishmaniasis affects 350 million people in 88 countries. It is estimated that 2 million new cases occur each year, with at least 12 million people presently infected worldwide (WHO, 2010). Depending on both the infecting vector species and the host immunological response to the pathogenic agent, leishmaniasis can be classified as tegumentary or visceral. The latter presents more severe symptoms and, in the New World, is caused by Leishmania chagasi.

The most common measures to control leishmaniasis rely on chemotherapy and vector control to reduce transmission (Handman, 2001). The first-line drug currently used in treatments is pentavalent antimony $\mathrm{Sb}(\mathrm{V})$, which was introduced at the beginning of 1940's (Herwaldt, 1999) and presents high toxicity. Moreover, an increase in clinical resistance to this drug has been reported (Lira et al., 1999; Mittal et al., 2007; Sen and Chatterjee, 2011). Second-line choice treatments include pentamidine and amphotericin $\mathrm{B}$, which are also toxic and too expensive for routine use in developing countries (Murray, 2001). Therefore, the necessity of new studies to find safe, less expensive and more effective treatments against leishmaniasis becomes evident.

Verbenaceae is a family consisting of more than 150 genera and about 2300 species widely distributed in tropical and subtropical regions (Cavalcanti et al., 2010). The species Lippia sidoides Cham. is a perennial bushy plant native to the Caatinga, which is rich in aromatic essential oils. The medicinal properties of $L$. sidoides essential oil include antifungal (Fontenelle et al., 2007), antibacterial (Oliveira et al., 2006; Lobo et al., 2011), anti-helminthic (Camurça-Vasconcelos et al., 2008), larvicidal, and acaricidal activities (Carvalho et al., 2003; Cavalcanti et al., 2010). Some of these biological properties are attributed to the presence of thymol and carvacrol in its essential oil (Carvalho et al., 2003; Botelho et al., 2007). The leishmanicidal activity of $L$. sidoides essential oil was recently demonstrated in promasitigote forms of $L$. chagasi (Oliveira et al., 2009) and L. amazonensis (Medeiros et al., 2011). Since in both studies thymol was the major component, further studies are needed to evaluate the leishmanicidal activity of essential oils with different compositions. Therefore, in the present study, we evaluated the inhibitory effect of a carvacrol-rich essential oil obtained from leaves of $L$. sidoides on promastigotes of L. chagasi.

\section{MATERIAL AND METHODS}

Plant material

Two accessions of L. sidoides (LSD102 and LSD104) were collected at Poço Redondo, Sergipe, Brazil ( $9^{\circ} 58^{\prime}$ 07,6" S; $37^{\circ}$ 
$51^{\prime} 49,2^{\prime \prime}$ W) and were cultivated in the Research Farm of the Universidade Federal de Sergipe, Department of Agronomical Engineering, São Cristóvão, Brazil. The leaves were harvested for essential oil extraction at the flowering stage. The voucher specimens of accessions LSD102 and LSD104, under numbers 8224 and 8226, respectively, are deposited at the Herbarium of Universidade Federal de Sergipe.

Dried and powdered leaves (75 g) were submitted to hydrodistillation in a Clevenger-type apparatus for 2 hours. At the end of each distillation the oils were collected and kept at a temperature of $-18^{\circ} \mathrm{C}$ for further analysis.

Analysis of the essential oils

Quantitative and qualitative analysis of the chemical composition of the essential oils were carried out using a gas chromatograph (Shimadzu, QP 5050A model) coupled to a mass spectrometer (MS) that was equipped with an autoinjector AOC-20i (Shimadzu) and a J\&W Scientific fused silica capillary column ( $30 \mathrm{~m}$ by $0.25 \mathrm{~mm}$; film thickness, $0.25 \mu \mathrm{m}$ ) with helium used as the gas carrier $(1.2 \mathrm{ml} / \mathrm{min})$. The MS was carried out with an ion capture detector operating in electronic impact mode, with an impact energy of $70 \mathrm{eV}$ The temperature was programmed to remain at $50{ }^{\circ} \mathrm{C}$ for $2 \mathrm{~min}$, followed by an increase at a rate of $4{ }^{\circ} \mathrm{C} / \mathrm{min}$ up to $200{ }^{\circ} \mathrm{C}$, then another increase of $15{ }^{\circ} \mathrm{C} / \mathrm{min}$ until $300{ }^{\circ} \mathrm{C}$ was reached, and maintained at this temperature for $15 \mathrm{~min}$. The injector and detector (or interface) temperatures were $250{ }^{\circ} \mathrm{C}$ and $280{ }^{\circ} \mathrm{C}$, respectively. Identification of the oil constituents was based on direct comparison of their spectra with spectra from the equipment database (NIST21 and NIST107) and from the literature (Adams, 2007). Additionally, the retention rates were compared to n-alkanes (C8-C18) injected under the same chromatographic conditions as the samples (Vandendool and Kratz, 1963).

\section{Parasite cultures}

Promastigoste forms were isolated from a patient of the University Hospital of Universidade Federal de Sergipe and coded as HUUFS14 (Ethics Committee number CAAE -0151.0.107.000-07). The isolate was characterized as Leishmania chagasi using monoclonal antibody and isoenzyme approaches. The culture was maintained by weekly transfer in Schneider's Drosophila medium (SigmaAldrich, St. Louis, MO, USA) supplemented with 10\% FBS (SigmaAldrich, St. Louis, MO, USA).

\section{Leishmanicidal Activity Assay}

The essential oils and major compounds (carvacrol, thymol and p-cymene) were initially dissolved in dimethyl sulfoxide (DMSO) at a concentration of $4 \%$. This solution was dissolved in culture medium to obtain a stock solution at $0.064 \%$. In a microplate (96 wells) this solution was serially diluted to concentrations ranging from 160 to $2.5 \mathrm{~nL} / \mathrm{mL}$ for essential oil, 64.0 to 0.5 for carvacrol and p-cymene and 200.0 to $1.6 \mu \mathrm{g} / \mathrm{mL}$ for thymol. Promastigotes $\left(1 \times 10^{5}\right.$ cells $)$ in the log phase of growth were seeded in each well and incubated for $24^{\circ} \mathrm{C} / 72 \mathrm{~h}$. Wells without oil and with amphotericin B were used as controls. In all cases the final concentration of DMSO never exceeded $0.4 \%$, a concentration which is not toxic for the protozoan (Oliveira et al., 2009).

The effect of essential oils on promastigote viability was assessed by 3-[4,5-dimethylthiazol-2-yl]-2,5-diphenyltetrasodium bromide (MTT) assay. After $72 \mathrm{~h}$ of treatment with essential oils, MTT $(1 \mu \mathrm{g} / \mathrm{ml}, \mathrm{pH} 7.4)$ was added in each well and the plate was incubated overnight in the dark at $24{ }^{\circ} \mathrm{C}$. After this, isopropanol $50 \%$ and Sodium Dodecyl Sulphate (SDS) $10 \%$ were added and the plate was incubated at $37^{\circ} \mathrm{C} / 4 \mathrm{~h}$, until the formazan crystals had been completely dissolved. Finally, the plate was read at 540 $\mathrm{nm}$ in a microplate reader (Labsystems apparatus multiskar MS).

All experiments were performed in triplicate. The concentration that inhibited culture growth by $50 \%\left(\mathrm{IC}_{50}\right)$ was determined by regression analysis. $\mathrm{IC}_{50}$ values were obtained in $\mathrm{nL} / \mathrm{mL}$ and were converted to $\mu \mathrm{g} / \mathrm{mL}$ based on oil and molecule densities.

\section{RESULTS}

The essential oils from two different accessions of L. sidoides (LSD102 and LSD104) were obtained with $6.7 \%$ and $6.8 \% \mathrm{w} / \mathrm{v}$ yield, respectively. Their chemical compositions were analyzed by GC/MS and the chromatograms are presented in Figure 1.

Fourteen (LSD102) and 15 (LSD104) compounds were identified and their retention indices and relative amounts, listed in order of elution, are shown on Table I. The oxygenated

\section{TABLE I}

Essential oil composition from accessions of $L$. sidoides characterized by GC/MS.

\begin{tabular}{llcc}
\hline RI & \multicolumn{1}{c}{ Compound } & $\begin{array}{c}\text { LSLSEO 102 } \\
\%\left(^{*}\right)\end{array}$ & $\begin{array}{c}\text { LSEO 104 } \\
\%\left(^{*}\right)\end{array}$ \\
\hline 924 & $\alpha$-Thujene & $1.1(1)$ & $1.7(1)$ \\
931 & $\alpha$-Pinene & $0.3(2)$ & $0.5(2)$ \\
988 & Myrcene & $3.3(3)$ & $3.5(3)$ \\
1006 & $\alpha$-Phellandrene & 0.0 & $0.2(4)$ \\
1007 & $\delta$ (3)Carene & $0.1(4)$ & $0.1(5)$ \\
1016 & $\alpha$-Terpinene & $1.9(5)$ & $3.1(6)$ \\
1024 & p-Cymene & $34.1(6)$ & $17.8(7)$ \\
1028 & Limonene & $0.5(7)$ & $0.4(8)$ \\
1035 & (Z)- $\beta$-Ocimene & 0.0 & $0.3(9)$ \\
1057 & $\gamma$-Terpinene & $6.8(8)$ & $16.6(10)$ \\
1180 & Terpinen-4-ol & $0.7(9)$ & $0.9(11)$ \\
1228 & Methyl thymol & $9.4(10)$ & $4.1(12)$ \\
1292 & Thymol & $38.7(11)$ & $6.0(13)$ \\
1298 & Carvacrol & $0.6(12)$ & $43.7(14)$ \\
1344 & Acetate thymol & $1.8(13)$ & 0.0 \\
1418 & $\beta$-Caryophyllene & $0.6(14)$ & 0.0 \\
1477 & NI & 0.0 & $0.8(15)$ \\
1506 & $\beta$-bisabolene & 0.0 & $0.2(16)$ \\
& Monoterpenes & 99.4 & 99.0 \\
& Sesquiterpenes & 0.6 & 0.2 \\
& Total & 100.0 & 99.2 \\
\hline & & & \\
\hline
\end{tabular}

RI: Relative retention index calculated against n-alkanes applying the Van den Dool equation

$\%$ : Compound percentage.

* Numbers inside parenthesis correspond to respective peaks in the chromatograms reproduced in Figure 1 
monoterpene thymol was the main component of the essential oil from accession LSD102 $(38.7 \%)$ while carvacrol was more abundant in LSD104 (43.7\%). Henceforth we will name the essential oil from LSD102 as LSEO102 and that from LSD104 as LSEO104.

In order to investigate the leishmanicidal activity, promastigotes of L. chagasi were incubated in the presence of increasing concentrations of LSEO102 and LSEO104 and cell viability was determined after 72 hours. As shown in Figure 2a, both essential oils inhibited parasite growth. The $\mathrm{IC}_{50}$ values obtained were 74.1 and $54.8 \mu \mathrm{g} / \mathrm{mL}$ for LSEO102 and LSEO104, respectively. In addition, we also evaluated the leishmanicidal potential of thymol and carvacrol, the main compounds of LSEO102 and LSEO104, respectively. Thymol exhibited an $\mathrm{IC}_{50}$ of $9.8 \mu \mathrm{g} / \mathrm{mL}$ and carvacrol, $2.3 \mu \mathrm{g} / \mathrm{mL}$.

\section{DISCUSSION}

The leishmanicidal and trypanocidal activity of essential oils from Lippia spp have been already demonstrated in some studies (Sulsen et al., 2006; Escobar et al., 2010). With regards to L. sidoides, leishmanicidal activity was demonstrated for the first time in promastigotes of $L$. chagasi with an $\mathrm{IC}_{50}$ of 89 $\mu \mathrm{g} / \mathrm{mL}$ (Oliveira et al., 2009). More recently, Medeiros et al.
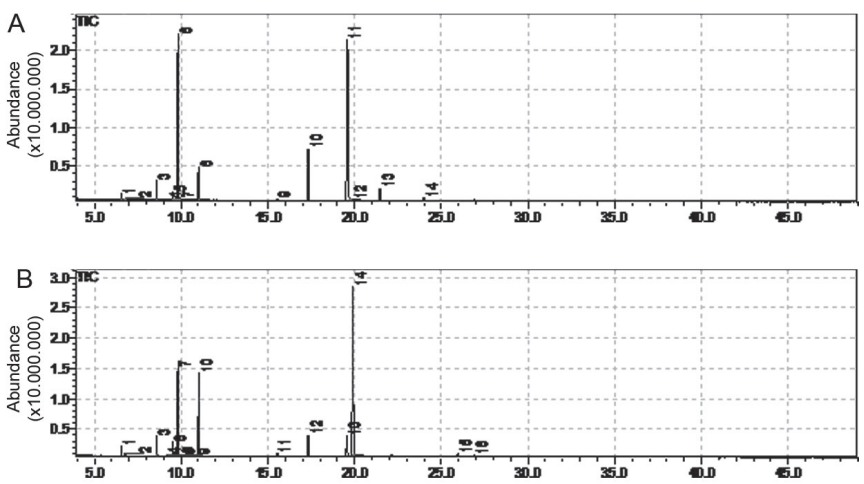

Figure 1: Total ion chromatogram (T) GC/MS chromatogram of essential oil from L. sidoides. A) LSEO 102. B) LSEO104

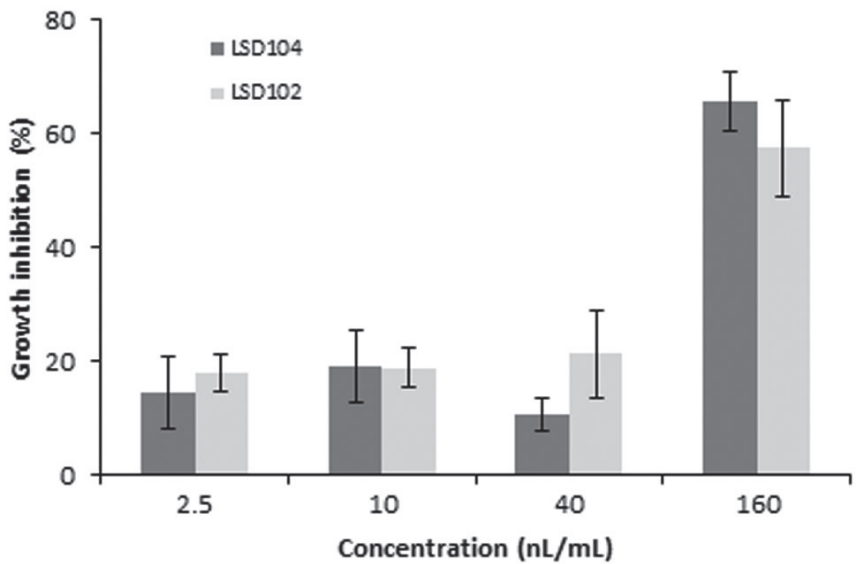

Figure 2: Effects of essential oil from accessions of $L$. sidoides on growth of $L$. chagasi promastigote forms. Each bar represents the mean \pm standard deviation of three independent experiments.
(2011) reported a more efficient activity of L. sidoides essential oil against promastigotes of $L$. amazonensis, since they found a lower $\mathrm{IC}_{50}(44.38 \mu \mathrm{g} / \mathrm{mL})$. In both studies, remarkable morphological changes in the parasite were observed and thymol was reported as the main constituent of the essential oils. It is important to note that the $\mathrm{IC}_{50}$ value obtained in our study for LSEO102 was similar to those obtained in the previous works (Oliveira et al., 2009; Medeiros et al., 2011).

Although a previous study has demonstrated the leishmanicidal activity of Lippia origanoides essential oil, with a relative amount of carvacrol greater than 35\% (Escobar et al., 2010), this is the first report on the leishmanicidal properties of essential oil from a new L. sidoides accession in which carvacrol, rather than thymol, is the main constituent. The composition of the carvacrol-rich essential oil herein evaluated (LSEO104) was similar to the one characterized by Cavalcanti et al. (2010). In that study, the authors verified that both the essential oil and pure monoterpene carvacrol showed acaricidal activity.

Interestingly, in the present study, the $\mathrm{IC}_{50}$ obtained for LSEO104 was lower than that found for LSEO102. Accordingly, carvacrol (LSEO104 major compound) presented $\mathrm{IC}_{50}$ lower than thymol (LSEO102 major compound). These results suggest that the greater efficiency of the carvacrol-rich essential oil against L. chagasi promastigotes probably is due to its major component. Although the relative amounts of thymol in LSEO102 and of carvacrol in LSEO104 are about 40\%, LSEO104 has $6 \%$ thymol in addition to the carvacrol content. On the other hand LSEO102 had no detectable amount of carvacrol in its composition. Therefore, we cannot rule out the contribution of a synergistic effect between thymol and carvacrol in LSEO104 for the greater leishmanicidal effect observed for this oil. It is important to note that, although relevant amounts of p cymene were detected in LSEO102 and LSEO104 $(34.1 \%$ and $17.8 \%$, respectively), this molecule did not show leishmanicidal effect in concentrations up to $64 \mathrm{~nL} / \mathrm{mL}$.

\section{CONCLUSIONS}

Our data show that $L$. sidoides essential oil is a natural product with leishmanicidal activity, suggesting its potential for the development of drugs against leishmania in the future. However, further studies are necessary to verify its effects on amastigote forms and its potential toxicity in vivo before clinical evaluation is performed.

\section{ACKNOWLEDGEMENTS}

The authors thank Saymo S. Fontes to help in essential oil extraction. Thanks to $\mathrm{CNPq}$ for the research productivity grants awarded to the fourth and sixth authors. Supported by FAPITEC/SE and CNPq.

\section{REFERENCES}

ADAMS RP (2007). Identification of Essential Oil Components by Gas Chromatography/Mass Spectrometry. Carol Stream, Ilinois, USA: Allured Publishing Corporation. pp: 804.

BEZERRA JL, COSTA GC, LOPES TC, CARVALHO ICDS, PATRÍCIO FJ, SOUSA SM, AMARAL FMM, REBELO JMM, GUERRA RNM, RIBEIRO MNS, NASCIMENTO FRF (2006). Evaluation of in vitro leishmanicidal activity of medicinal plants. Brazil J Pharmacog 16 (supp): 631-637.

BOTELHO MA, NOGUEIRA NA, BASTOS GM, FONSECA SG, LEMOS TL, MATOS FJ, MONTENEGRO D, HEUKELBACH J, RAO VS, BRITO GA (2007). Antimicrobial activity of the essential oil from Lippia sidoides, 
carvacrol and thymol against oral pathogens. Braz J Med Biol Res 40: 349-356.

CAMURÇA-VASCONCELOS AL, BEVILAQUA CM, MORAIS SM, MACIEL MV, COSTA CT, MACEDO IT, OLIVEIRA LM, BRAGA RR, SILVA RA, VIEIRA LS, NAVARRO AM (2008). Anthelmintic activity of Lippia sidoides essential oil on sheep gastrointestinal nematodes. Vet Parasitol 154: 167-170.

CARVALHO AF, MELO VM, CRAVEIRO AA, MACHADO MI, BANTIM MB, RABELO EF (2003). Larvicidal activity of the essential oil from Lippia sidoides Cham. Against Aedes aegypti linn. Mem Inst Oswaldo Cruz 98: 569-571.

CAVALCANTI SC, NICULAU EDOS S, BLANK AF, CAMARA CA, ARAUJO IN, ALVES PB (2010). Composition and acaricidal activity of Lippia sidoides essential oil against two-spotted spider mite (Tetranychus urticae Koch). Bioresour Technol 101: 829-832.

ESCOBAR P, LEALL SM, HERRERA LV, MARTINEZ JR, STASHENKO E (2010). Chemical composition and antiprotozoal activities of Colombian Lippia spp essential oils and their major components. Mem Inst Oswaldo Cruz 105: 184-190.

FONTENELLE RO, MORAIS SM, BRITO EH, KERNTOPF MR, BRILHANTE RS, CORDEIRO RA, TOME AR, QUEIROZ MG, NASCIMENTO NR, SIDRIM JJ, ROCHA MF (2007). Chemical composition, toxicological aspects and antifungal activity of essential oil from Lippia sidoides Cham. J Antimicrob Chemother 59: 934-940.

FRANCA F, LAGO EL, MARSDEN PD (1996). Plants used in the treatment of leishmanial ulcers due to Leishmania (Viannia) braziliensis in an endemic area of Bahia, Brazil. Rev Soc Bras Med Trop 29: 229-232.

HAMMER ML, JOHNS EA (1993). Tapping an Amazonian plethora: four medicinal plants of Marajo Island, Para (Brazil). J Ethnopharmacol 40: 53-75

HANDMAN E (2001). Leishmaniasis: current status of vaccine development. Clin Microbiol Rev 14: 229-243.

HERWALDT BL (1999). Leishmaniasis. Lancet 354: 1191-1199.

LIRA R, SUNDAR S, MAKHARIA A, KENNEY R, GAM A, SARAIVA E, SACKS D (1999). Evidence that the high incidence of treatment failures in Indian kala-azar is due to the emergence of antimony-resistant strains of Leishmania donovani. J Infect Dis 180: 564-567.
LOBO PL, FONTELES CS, DE CARVALHO CB, DO NASCIMENTO DF, DA CRUZ FONSECA SG, JAMACARU FV, DE MORAES ME (2011). Doseresponse evaluation of a novel essential oil against Mutans streptococci in vivo. Phytomed 18: 551-556.

MEDEIROS MG, SILVA AC, CITÓ AM, BORGES AR, LIMA SG, LOPES JA, FIGUEIREDO RC (2011). In vitro antileishmanial activity and cytotoxicity of essential oil from Lippia sidoides Cham. Parasitol Int 60: 237-241.

MEDEIROS MG, SILVA AC, CITO AM, BORGES AR, LIMA SG, LOPES JA, FIGUEIREDO RC (2011). In vitro antileishmanial activity and cytotoxicity of essential oil from Lippia sidoides Cham. Parasitol Int 60: 237-241.

MITTAL MK, RAI S, ASHUTOSH, RAVINDER, GUPTA S, SUNDAR S, GOYAL N (2007). Characterization of natural antimony resistance in Leishmania donovani isolates. Am J Trop Med Hyg 76: 681-688.

MURRAY HW (2001). Clinical and experimental advances in treatment of visceral leishmaniasis. Antimicrob Agents Chemother 45: 2185-2197.

OLIVEIRA FP, LIMA EO, JÚNIOR JPS, SOUZA EL, SANTOS BHC, BARRETO HM (2006). Effectiveness of Lippia sidoides Cham. (Verbenaceae) essential oil in inhibiting the growth of Staphylococcus aureus strains isolated from clinical material. Braz J Pharmacog 16: 510516.

OLIVEIRA VC, MOURA DM, LOPES JA, DE ANDRADE PP, DA SILVA NH, FIGUEIREDO RC (2009). Effects of essential oils from Cymbopogon citratus (DC) Stapf., Lippia sidoides Cham., and Ocimum gratissimum L. on growth and ultrastructure of Leishmania chagasi promastigotes. Parasitol Res 104: 1053-1059.

SEN R, CHATTERJEE M (2011). Plant derived therapeutics for the treatment of Leishmaniasis. Phytomed 18: 1056-1069.

SULSEN V, GUIDA C, COUSSIO J, PAVETO C, MUSCHIETTI L, MARTINO $\mathrm{V}$ (2006). In vitro evaluation of trypanocidal activity in plants used in Argentine traditional medicine. Parasitol Res 98: 370-374.

VANDENDOOL H, KRATZ PD (1963). A Generalization of the Retention Index System Including Linear Temperature Programmed Gas-Liquid Partition Chromatography. J Chromatogr 11: 463-471.

WHO (2010). Control of the leishmaniasis: report of a meeting of the WHO expert committee on the control of leishmaniasis, Geneva: World Health Organization. pp: 202 